\title{
Phospholipids: Pulling Back the Actin Curtain for Granule Delivery to the Immune Synapse
}

\author{
Christian M. Gawden-Bone* and Gillian M. Griffiths \\ Cambridge Institute of Medical Research, University of Cambridge, Cambridge, United Kingdom
}

Phosphoinositides, together with the phospholipids phosphatidylserine and phosphatidic acid, are important components of the plasma membrane acting as second messengers that, with diacylglycerol, regulate a diverse range of signaling events converting extracellular changes into cellular responses. Local changes in their distribution and membrane charge on the inner leaflet of the plasma membrane play important roles in immune cell function. Here we discuss their distribution and regulators highlighting the importance of membrane changes across the immune synapse on the cytoskeleton and the impact on the function of cytotoxic T lymphocytes.

OPEN ACCESS

Edited by:

Jorge Bernardino De La Serna, Imperial College London, United Kingdom

Reviewed by:

Marek Cebecauer,

J. Heyrovsky Institute of Physical

Chemistry (ASCR), Czechia

Manuel Izquierdo,

Spanish National Research Council

(CS/C), Spain

${ }^{*}$ Correspondence:

Christian M. Gawden-Bone cmg59@cam.ac.uk

Specialty section:

This article was submitted to $T$ Cell Biology,

a section of the journal

Frontiers in Immunology

Received: 31 October 2018 Accepted: 14 March 2019 Published: 11 April 2019

Citation:

Gawden-Bone CM and Griffiths GM (2019) Phospholipids: Pulling Back the Actin Curtain for Granule Delivery to the Immune Synapse.

Front. Immunol. 10:700. doi: 10.3389/fimmu.2019.00700
Keywords: T cells, cytotoxic T lymphocytes (CTLs), phospholipids, phosphatidylinositol 4,5-bisphosphate (PI(4,5)P2), diacylglycerol (DAG), phosphatidylinositol 3,4,5-trisphosphate (PI(3,4,5)P3)

\section{CYTOTOXIC T CELLS, THE IMMUNE SYNAPSE AND PHOSPHOLIPIDS}

Cytotoxic T lymphocytes (CTLs) are important for the clearance of cancerous and virally infected cells. Their task is more difficult as cancers and virally infected organs present as a mosaic of diseased and healthy cells within the tissue. CTLs specifically target infected or cancerous cells using the T cell receptor (TCR) recognizing peptide-loaded, major histocompatibility complex class one (pMHC I) on the surface of an antigen presenting cell [APC; reviewed in (1)]. TCR activation triggers a cascade of signaling events that results in the formation of a characteristic cell-to-cell contact between APCs and the CTLs referred to as the immune synapse [reviewed in (2)]. In CTL TCR clusters at the center of the synapse and lytic granule secretion occurs at a specialized secretory domain, next to the site of signaling $(3,4)$.

Actin depletion is an essential event that regulates lytic granule secretion at the synapse of both CTLs and natural killer cells (5-8). Although phospholipids and phosphoinositides have been well-characterized as regulators of actin reorganization during phagocytosis and macropinocytosis (9), their role in actin reorganization at the synapse has only recently emerged with more accurate lipid probes allowing visualization of their distribution and regulation across the synapse (10).

Figure 1 shows the metabolic pathways involved in lipid signaling events within the plasma membrane and endocytic system. Upon initial contact between the CTLs and APCs, F-actin initially accumulates across the forming interface before rapidly depleting as TCR activation triggers changes in the lipid composition across the immune synapse $(7,11)$. These changes are initiated by TCR activation of the LAT signalosome with Slp76, Gads and phospholipase C gamma 1 (PLC $\gamma 1)$ which rapidly accumulates in clusters as the synapse forms, recruiting other effector proteins that together potentiate signaling $(12,13)$. DAG, the product of PLC $\gamma 1$ mediated cleavage of phosphatidylinositol 4,5-bisphosphate (PI(4,5)P2), accumulates as PI(4,5)P2 diminishes across the synapse. Together with other changes an area of membrane specialization is formed (Figure 2). 


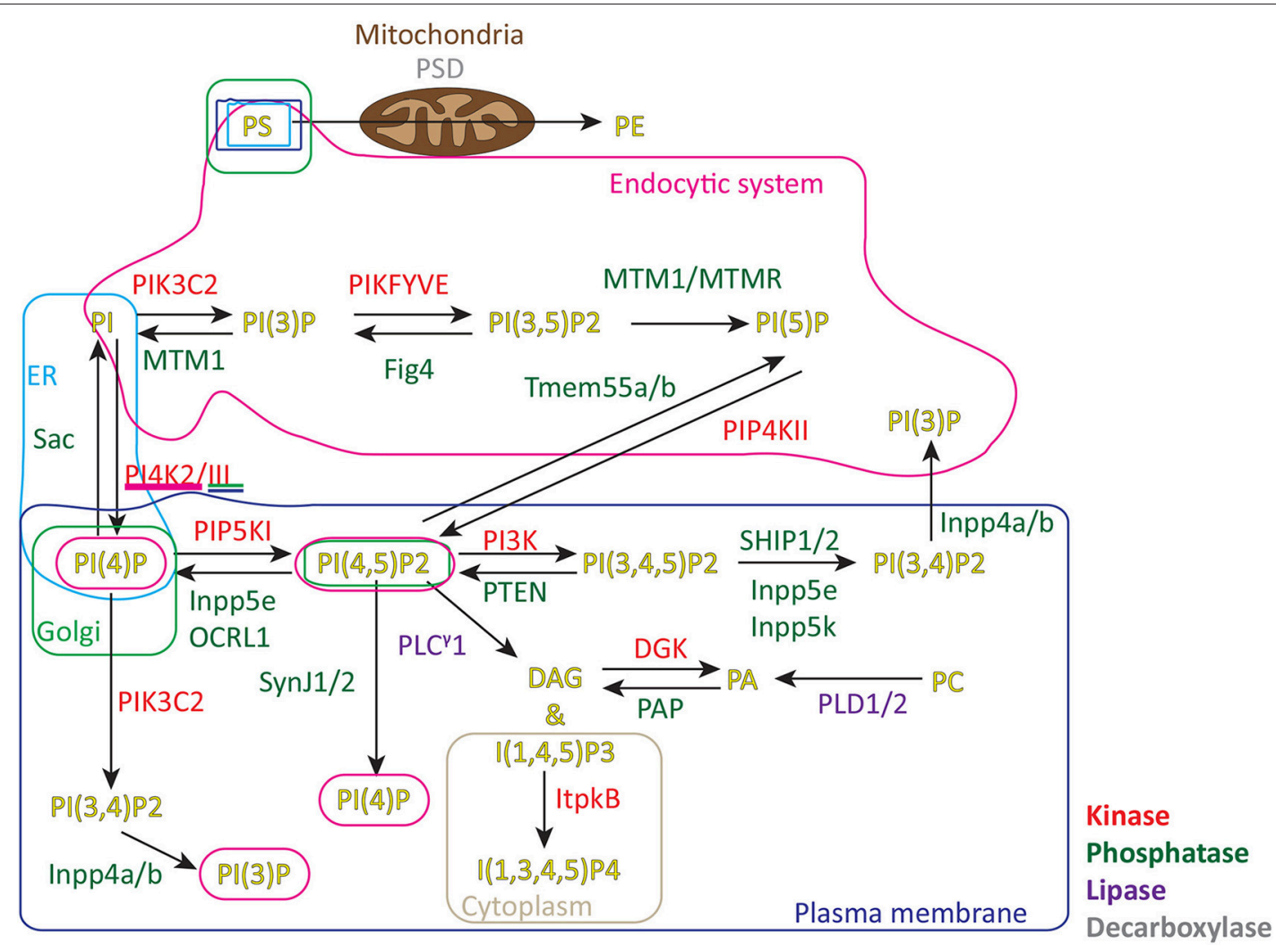

FIGURE 1 | Metabolic pathways and location of signaling lipids in cells. PS, phosphatidylserine; PE, phosphatidylethanolamine; PA, phosphatidic acid; PC, phosphatidylcholine; PI, phosphatidylinositol; PI(3)P, phosphatidylinositol 3-phosphate; PI(4)P, phosphatidylinositol 4-phosphate; PI(5)P, phosphatidylinositol 5-phosphate; PI(4,5)P2, phosphatidylinositol 4,5-bisphosphate; PI(3,4)P2, phosphatidylinositol 3,4-bisphosphate; PI(4,5)P2, phosphatidylinositol 3,5-bisphosphate; PI(3,4,5)P3, phosphatidylinositol 3,4,5-trisphosphate; DAG, diacylglycerol; I(1,4,5)P3, inositol 1,4,5-trisphosphate; I(1,3,4,5)P4, inositol 1,3,4,5-tetrakisphosphate; PSD, phosphatidylserine decarboxylase; PIK3C2, Phosphatidylinositol 4-phosphate 3-kinase C2 domain-containing subunit $\alpha / \beta / \gamma$; PIKFYVE, Phosphatidylinositol 3-phosphate 5-kinase/FYVE finger-containing phosphoinositide kinase; MTM1/MTMR, Myotubularin/Myotubularin related 1-14; Fig4 Polyphosphoinositide phosphatase; Tmem55b/a, Type 2 phosphatidylinositol 4,5-bisphosphate 4-phosphatase/Type 1 phosphatidylinositol 4,5-bisphosphate 4-phosphatase; PIP4KII Phosphatidylinositol 5-phosphate 4-kinase type-2 $\alpha / \beta / \gamma$; PI4K2/lll, Phosphatidylinositol 4-kinase type $2 \alpha / \beta /$ Phosphatidylinositol 4-kinase $\alpha / \beta$; PIP5K, Phosphatidylinositol 4-phosphate 5-kinase $\alpha / \beta / \gamma$; PI3K, Phosphatidylinositol 4,5-bisphosphate 3-kinase $\alpha / \beta / \gamma / \delta$; SHIP1/2, SH2 domain-containing inositol 5'-phosphatase 1/SH2 domain-containing inositol 5'-phosphatase 2; Inpp5e, Inositol polyphosphate 5-phosphatase E; OCRL1, Inositol polyphosphate 5-phosphatase; SynJ1/2, Synaptic inositol 1,4,5-trisphosphate 5-phosphatase1/2; PTEN, Phosphatidylinositol 3,4,5-trisphosphate 3-phosphatase and dual-specificity protein phosphatase; Inpp5k, Inositol polyphosphate 5-phosphatase K; PLC $\gamma 1$, phospholipase C $\gamma 1$; DGK, diacylglycerol kinase $/ \zeta$ PAP PLD1/2 phospholipase D1/2; Inpp4a/b, Type I inositol 3,4-bisphosphate 4-phosphatase/Type II inositol 3,4-bisphosphate 4-phosphatase; ER, endoplasmic reticulum.

Abbreviations: MHC I, Major histocompatability complex I; TCR, T cell receptor; CTL, Cytotoxic T lymphocyte; PI(3)P, Phosphatidylinositol 3-phosphate; PI(4)P, Phosphatidylinositol 4-phosphate; PI(5)P, Phosphatidylinositol 5phosphate; PI(4,5)P2, Phosphatidylinositol 4,5-bisphosphate; PI(3,4,5)P3, Phosphatidylinositol 3,4,5-trisphosphate; PI (3,4)P2, Phosphatidylinositol 3,4-bisphosphate; PI(3,5)P2, Phosphatidylinositol 3,5-bisphosphate; DAG, Diacylglycerol; PS, Phosphatidylserine; PA, Phosphatidic acid; IP3, Inositol 1,4,5 trisphosphate; IP4, Inositol 1,3,4,5 tetrakisphosphate; APC, Antigen presenting cells; LAT, Linker for activation of T cells; PLC $\gamma 1$, Phospholipase C gamma 1; ItpkB, Inositol 1,4,5-trisphosphate 3-kinase B; PI3K, Phosphatidylinositol 4,5bisphosphate 3-kinase; PIP4KII, Phosphatidylinositol 5-phosphate 4-kinase; PIP5K, Phosphatidylinositol 4-phosphate 5-kinase; DGK, Diacylglycerol kinase; PTEN, Phosphatidylinositol 3,4,5-trisphosphate 3-phosphatase and dual-specificity protein phosphatase; SHIP1, SH2 domain-containing inositol 5' -phosphatase 1; FERM, 4.1 protein/Ezrin/Radaxin/Moesin; ERM, Ezrin/Moesin/Radaxin; WASp, Wiskott-Aldrich syndrome protein; TIRFM, Total internal reflection microscopy; PKC, Protein kinase C; PKD, Protein kinase D; IFT20, Intraflagella transport 20; ICAM-I, Intercellular adhesion molecule I; TAPP1, Tandem PH domain-containing protein 1; PH domain, Pleckstrin homology domain; Grp1, General receptor of phosphoinositides 1; FYVE, Fab 1/YOTB/Vac 1/EEA1; F-actin, Filamentous actin; Zap70, $70 \mathrm{kDa}$ zeta-chain associated protein; LFA-1, Leukocyte function-associated molecule 1.

\section{LIPID REGULATION GENERATES MEMBRANE SPECIALIZATION}

Low levels of phosphoinositides in membranes allow for exquisite regulation of signaling, with small changes modulating recruitment of signaling proteins. In CTLs the key event in response to changes initiated by TCR activation of PLC $\gamma 1$ is the loss of $\mathrm{PI}(4,5) \mathrm{P} 2$ across the immune synapse, which results in a loss of cortical actin across the membrane, allowing granule secretion to occur (10). Equally important to events driving the loss of actin across the synapse are the mechanisms that prevent $\mathrm{PI}(4,5) \mathrm{P} 2$ being rapidly replenished by the PIP5 kinases (PIP5K). Although PIP5K family members are recruited to the immune synapse in Jurkat cells, these studies did not examine dynamic temporal events $(14,15)$. When PIP5K dynamics were examined it was found that these kinases are also depleted across the synapse upon TCR activation, and the ability to replenish $\mathrm{PI}(4,5) \mathrm{P} 2$ via this pathway is also lost 


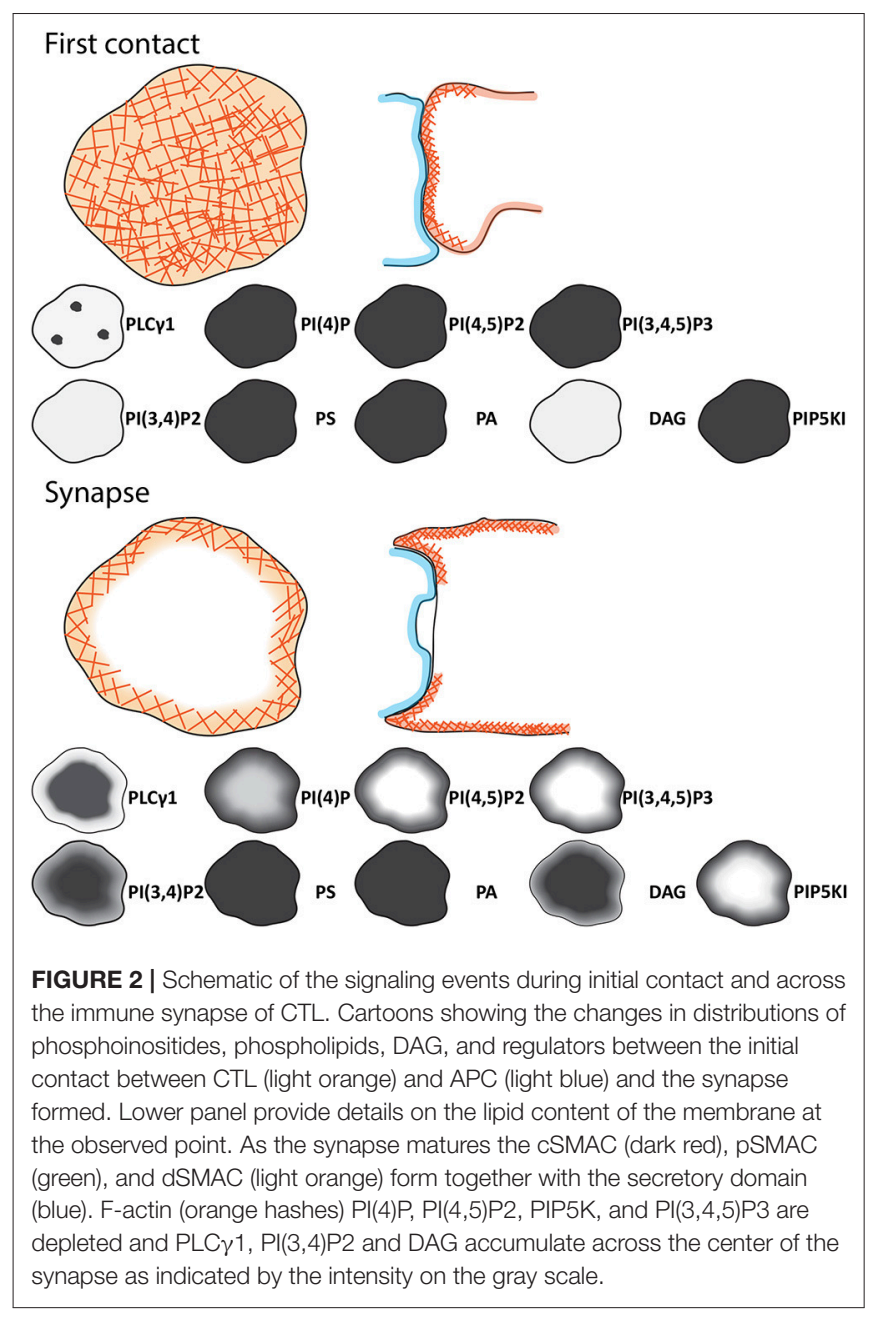

(10). Exactly how this coordinated loss of PI $(4,5) \mathrm{P} 2$ and the kinase that usually maintains $\mathrm{PI}(4,5) \mathrm{P} 2$ levels in the plasma membrane occurs in response to TCR activation also emerged from these studies. Several different mechanisms have been shown to control PIP5K membrane association in different cell types, including recruitment via Rac1, ARF6, AP-2, betaarrestin, talin, and PI(4)P (16-20). However, in macrophages the mechanism for PIP5K membrane association occurs via an electrostatic switch, by virtue of a series of polybasic amino acids that project from a conserved alpha-helix and interact with negatively charged $\mathrm{PI}(4,5) \mathrm{P} 2$ in the membrane $(21,22)$. This electrostatic mechanism also functions in $\mathrm{T}$ cells and provides a very elegant way of coupling TCR activation with membrane changes that control secretion. Upon TCR activation the loss of PI(4,5)P2 by PLC $\gamma 1$ also causes a loss of negative charge as DAG replaces $\mathrm{PI}(4,5) \mathrm{P} 2$. This rapid loss of negative charge causes PIP5K to dissociate from the plasma membrane across the synapse so that $\mathrm{PI}(4,5) \mathrm{P} 2$ can no longer be replenished via this route. This rapid loss of $\mathrm{PI}(4,5) \mathrm{P} 2$ drives a rapid loss of actin favoring granule secretion (10). In this way, a small shift in the balance of phosphoinositides is able to control CTL killing.

One challenge to maintaining lipid specialization is that most lipids are highly diffusible within the plasma membrane. DAG has been reported to be a highly diffusible lipid when tracked with the PKC-theta $\mathrm{C} 1$ domain probe in B cells (23); nevertheless a DAG gradient is maintained at the synapse membrane by the interplay of lipases and kinases (24). Using diacylglycerol kinase (DGK) $\alpha$ or $\zeta$ null mice and TIRFM on activating membranes this study shows that CD8 and CD4 T cells deficient in DGK $\alpha$ have a centrosome polarization defect. This was due to the diffuse distribution of DAG across the synaptic membrane suggesting that the restriction of DAG in the cSMAC is an important feature for centrosome recruitment to the membrane and that DGK $\alpha$ acts to ensure the focus of DAG in the membrane. Importantly, DGK $\alpha$ localized to the dSMAC suggesting it fences in the DAG to the central synapse (24). Any DAG that moves toward the periphery at the concentration of active DGK $\alpha$ is metabolized to PA, which may also constrain RasGrp signaling to the central synapse $(25,26)$. This limits DAG to a relatively tight area of the membrane and this in turn maintains the polarizing signal (24). More importantly, DAG would create a spatially regulated docking site for centrosome delivery to the synapse. DGK $\zeta$ deletion had no effect on the spatial regulation of DAG at the synapse and did not prevent centrosome polarization (24). Although, the role of DGK $\zeta$ is less clear at the synapse where it is implicated in the regulation of signal strength at the synapse through its control of the Ras and Erk pathways (27).

Intriguingly many other proteins have specific domains or positively charged outer surfaces that allow sensing of charge changes at the plasma membrane [reviewed in (21),(28-32)]. A number of synthetic probes exist to detect charge in the membrane, based on arginine and lysine rich amino acid chains, with a lipidation motif at their C-terminus. These include the Kras +8 probe, R-pre probe, and the MCS+ probe based on $\mathrm{R}$-pre [described in detail in (32-34)]. The drop in charge in both the CTL synapse and in Jurkat cells has been detected with these probes $(10,33)$, suggesting this is a general mechanism for modulating the immune synapse membrane.

\section{PI(4,5)P2, PIP5K, AND PLC $\gamma 1$ REGULATE THE ACTIN CYTOSKELETON IN THE SYNAPSE}

F-actin dynamics at the synapse are important for TCR signaling and delivery of granules to the synapse membrane $(7,35,36)$. Several lines of evidence support a link between the loss of PI $(4,5) \mathrm{P} 2$ and the loss of actin across the synapse. First, the loss of PI $(4,5) \mathrm{P} 2$ correlates both spatially and temporally with the loss of actin [(7); Figure 2]. Second, the phospholipase C inhibitor, U73122, which inhibits PLC $\gamma 1$, blocks actin loss from the central synapse region. Thirdly, blocking the depletion of PIP5K proteins from the synapse by tagging PIP5K $\beta$ with the palmitoylation domain of Lyn protein, blocks actin depletion across the synapse.

The role of $\mathrm{PI}(4,5) \mathrm{P} 2$ in recruiting actin to the cortical membrane is mediated by a number of actin-recruiting proteins that bind directly to $\mathrm{PI}(4,5) \mathrm{P} 2$. These include the Ezrin/Radaxin/Moesin (ERM) proteins which interact with PI $(4,5)$ P2 via their FERM domains (37). Phosphorylation of ERM proteins stabilizes their open conformation and allows for bridging of the actin cytoskeleton and $\operatorname{PI}(4,5) \mathrm{P} 2(38,39)$. 
PIP5Ks have also been shown to recruit ERM to the membrane of primary 5C.C7 TCR T cells by production of PI(4,5)P2 (40). Interestingly, ERM proteins deplete across the CD4 $\mathrm{T}$ cell synapse after initial contact between T cell and APC (41). Furthermore, cleavage of PI(4,5)P2 by PLC $\gamma 1$ triggers depletion of Ezrin from the membrane in CTLs (39).

Wiskott-Aldrich syndrome protein (WASp) also plays a role in actin recruitment, interacting directly with $\mathrm{PI}(4,5) \mathrm{P} 2$ via a polybasic region. Interestingly, WASp has a direct role in TCR activation and regulation of PLC $\gamma 1$ activity in the CTL membrane. WASp recruitment to TCR complexes is thought to be required for efficient activation of TCR and the subsequent recruitment of PLC $\gamma 1, \operatorname{PI}(4,5) \mathrm{P} 2$ metabolism and calcium signaling; all of which were defective in WASp null T cells (36). This suggests that TCR activation via WASp occurs early in signaling when the membrane has abundant levels of $\mathrm{PI}(4,5) \mathrm{P} 2$, or occurs later at the periphery of the maturing synapse where $\mathrm{PI}(4,5) \mathrm{P} 2$ is also abundant. Alternatively, low levels of PI(4,5)P2 present in the central synapse might be sufficient to recruit WASp, or perhaps WASp might be recruited via $\mathrm{PI}(3,4) \mathrm{P} 2$, which is a mirror image of the $\mathrm{PI}(4,5) \mathrm{P} 2$ and is abundant at the central synapse membrane.

\section{PI(3,4,5)P3 DISTRIBUTIONS LEAD TO FORCES ACROSS THE SYNAPSE}

Most research to date has focused on understanding the interplay of signaling proteins on the CTL side of the immune synapse. However, this is only half the story in the interaction between $\mathrm{T}$ cell and target. The membrane tension generated on the target side of the synapse is an important regulator of perforin-mediated killing. Phosphoinositides, actin and integrins are all thought to mediate forces sensed by the target. The phosphoinositide $\mathrm{PI}(3,4,5) \mathrm{P} 3$ controls actin movement in the periphery through Rac1 activity, a potent regulator of actin cytoskeletal dynamics. These actin mediated forces are focused in the dSMAC where engulfment and cell motility protein 1 (ELMO) is recruited to the plasma membrane via $\mathrm{PI}(3,4,5) \mathrm{P} 3$. Here it interacts with dedicator of cytokinesis protein 2 (DOCK2) activating Rac1 to initiate WAVE driven actin dynamics (42).

More recently a role for $\mathrm{PI}(3,4,5) \mathrm{P} 3$ in force generation at the synapse was demonstrated using deflection of micropillars to measure forces. Consistent with the earlier findings, loss of DOCK2 resulted in a loss of force across the synapse (43). This elegant system was also able to reveal force direction and showed that early forces pushed in to the periphery in a process termed mechanopotentiation. These results suggested that these forces, which were myosin II dependent and were increased when PTEN was silenced, increased membrane tension across the APC membrane, potentiating perforin-mediated killing $(35,43)$.

Integrin interactions, supported by the local lipid microenvironment, also play an important role in generating actin-driven forces across the synapse. Integrin activators kindlin-3 and talin, which stabilize the extended conformation of the integrin in to the extracellular milieu, depend on the presence of $\mathrm{PI}(3,4,5) \mathrm{P} 3$ and $\mathrm{PI}(4,5) \mathrm{P} 2(44,45)$. Kindlin-3 may be dispensable for synapse formation and integrin activation in T cells (46-48), whereas talin and vinculin's interaction with integrins drives TCR responses in CD4 T cells (49). $\mathrm{PI}(3,4,5) \mathrm{P} 3$ is thought to drive actin flow at the periphery of the synapse which in turn regulates integrin and WAVE activation (43). Integrins are drawn in the direction of the actin flow in CTLs, with continued ruffling between CTLs and APC generating tension (50). The actin cytoskeleton in the dendritic cell also supports T cell interaction through the stabilization of ICAM-1 contributing to the forces generated (51). Although the direction of actin flow in the synapse is controversial, with TIRF imaging interpreted as showing a centripetal inward flow of actin to the dSMAC (52), while lattice light sheet showed a rearward flow of peripheral lamellipodial actin toward the uropod of CTL (7), the direction of actin flow in the synapse will have an important role in integrin activation and forces generated at the synapse.

TCR activation in the periphery also drives inside out integrin activation and tension creation, as CasL, a phosphoprotein with multiple kinase docking sites is recruited to the peripheral TCR complexes and support larger TCR clusters when present. CasL recruitment led to integrin activation at the immune synapse (53), further building on the hypothesis that continued actin dynamics, TCR activation and integrin activation support each other in synapse formation. Activation of integrin leukocyte function-associated molecule 1 (LFA-1; CD11a/CD18 heterodimer) in the CD4 $\mathrm{T}$ cell immune synapse results in a significant increase in TCR activation (49, 54, 55). TCR activation, actin dynamics and integrin adhesion in the periphery clearly increase further TCR:MHCI interactions, potentiating signaling and synapse lifetime. This may suggest why $\mathrm{PI}(3,4,5) \mathrm{P} 3$ supported actin dynamics in the distal synapse region is important for CTL killing.

\section{DIACYLGLYCEROL AT THE IMMUNE SYNAPSE}

As already mentioned phosphoinositide changes play a role in directing granules to the synapse. DAG, generated by the initial cleavage of $\mathrm{PI}(4,5) \mathrm{P} 2$, controls the movement of the centrosome to the synapse membrane through its activation of kinases and motor proteins (56-58). Inositol 1,4,5-trisphosphate (IP3) either binds receptors in the endoplasmic reticulum activating calcium release from intracellular stores or is converted into IP4 and involved in ITK signaling (59). The importance of DAG is clear from studies in which the conversion of PI(4,5)P2 to DAG or un-caging of DAG (independent of calcium signaling) by fluorescence activation are sufficient to polarize the centrosome to the plasma membrane (58). Computer modeling of DAG in membranes suggests that DAG is a mediator of gross biophysical changes within the membrane due to changes in head group spacing and hydrophobic fatty acid packing. These changes in local membrane spacing would allow for improved localization of the DAG dependent protein kinase C (PKC) family members and $\mathrm{C} 1$ domain containing proteins (60). DAG plays many other roles at the synapse, supporting the activation of PKC family members, protein kinase D (PKD) and RAS guanyl-releasing protein/RasGRP $(57,61,62)$. 
Production of DAG at the $\mathrm{T}$ cell synapse membrane is important for recruiting $\mathrm{PKD}$. $\mathrm{PKC} \beta$, which is a transient resident of the synapse, activates $\mathrm{PKD}$ at the synapse after DAG binding $(57,62)$. There are multiple targets for PKD after activation including transcription factors, the actin cytoskeleton and multiple serine/threonine and tyrosine kinases. This suggests that formation of DAG at the synapse has a significant effect on the post-translational and transcriptional profile of the CTL (63).

Recruitment of the Tec kinase, ITK relies on PI $(3,4,5) \mathrm{P} 3$ for its localization and this is enhanced by pleckstrin homology (PH) domain binding of IP4. Inositol 1,4,5-trisphosphate (IP3) 3-kinase B (ItpkB) generates IP4 after PLC $\gamma 1$ converts PI $(4,5)$ P2 to DAG and IP3. T cells from ItpkB deficient mice were unable to recruit ITK to the immune synapse. T cells recruited less DAG at the synapse and displayed reduced Erk signaling, which may explain why ItpkB null mice have a $\mathrm{T}$ cell deficiency (64). This suggests that ItpkB and ITK may act as a signal multiplier, supporting large-scale activation of PLC $\gamma 1$ at the synapse. This in turn generates more substrate for ItpkB that supports further ITK activation. ITK null CTLs show reduced killing capacity suggesting it does not only affect differentiation of $\mathrm{T}$ cell or $\mathrm{T}$ cell selection but also regulates effector cell function (65). Mathematical modeling of how IP4 levels play a role in enhancing ITK activation through increased $\mathrm{PI}(3,4,5) \mathrm{P} 3 / \mathrm{PH}$ domain binding, indicated there is also a negative feedback loop regulating the pathway. As IP4 increases due to continued activation of PLC $\gamma 1$ and activity of ItpkB, IP4 outcompetes the $\mathrm{PI}(3,4,5) \mathrm{P} 3$ binding site in the $\mathrm{PH}$ domain. This results in dissociation of ITK from the membrane and loss of PLC $\gamma 1$ activation through ITK activity (66). ITK/ItpkB/IP4/ may therefore regulate the total available DAG created at the membrane during synapse formation independently of other signaling events and ITK through this signaling negative feedback loop may regulate $\mathrm{T}$ cell activation and lipid dynamics. Pleckstrin2 is also recruited to the plasma membrane including the synapse of Jurkat cells via the $\mathrm{PH}$ domain, co-localizing with actin (67) although the mechanism is not as thoroughly studied as for Itk yet.

\section{PHOSPHATIDYLSERINE AND PHOSPHATIDIC ACID AT THE SYNAPSE}

Several other species of phospholipids contribute to membrane specialization in cells including PI(5)P, PI(3)P, PS, PA, and $\mathrm{PI}(3,5) \mathrm{P} 2$ (Figure 1). Many have specific functions in pathways such as endosome sorting, membrane charge, endocytosis and autophagy. PS is a negatively charged phospholipid; however, it is not significantly depleted from the central synapse region as negative charge decreases $(10,33)$. It is possible that the influx of positive ions (such as $\mathrm{Ca} 2+$ or $\mathrm{Mg} 2+$ ) during TCR signaling may neutralize the charge of these lipid head groups during the charge depletion event, as seen in macrophages where calcium influx limited plasma membrane charge $(32,33,68)$. In some CTL, PS appeared to concentrate at the actin-rich distal region of the synapse; F-actin is reported to slow down PS dynamic in the membrane as PS transiently binds with actin-membrane linker proteins (69).

PA, which is the product of DAG phosphorylation by DGK, does not appear to change across the synapse as it forms, suggesting that DAG is not significantly modified during synapse formation (10). This is important, as PA in the plasma membrane has been shown to regulate PIP5K activity (70). As PA does not increase while actin recovers this implies that it is unlikely to be responsible for the recovery of PIP5K, PI(4,5)P2, and actin observed after granule secretion (8).

Several lipids are yet to be visualized in the synapse in $\mathrm{T}$ cells as the probes used to investigate their distribution are not specific (71) or express poorly in CTLs. However, it has been shown that phosphatidylinositol 5-phosphate (PI(5)P) can be produced via other routes including the 4'-phosphatase activity of Tmem $55 \mathrm{a} / \mathrm{b}$ on PI(4,5)P2 (Figure 1); myotubularin 3'phosphatases acting on $\mathrm{PI}(3,5) \mathrm{P} 2$ and inhibition of PIP4K activity or the expression of IpgD (72-74). Interestingly, PI(5)P increases have been shown to lead to increases in cytokine production and Src family kinase signaling in activated $\mathrm{T}$ cells $(72,75,76)$. Until specific protein sensors become available, information on these lipids is limited.

\section{MEMBRANE SPECIALIZATION ACROSS THE PRIMARY CILIUM AND THE IMMUNE SYNAPSE}

One of the most remarkable findings about the phosphoinositide specialization observed across the synapse is its striking similarity to the phosphoinositide signature across the primary cilium with $\mathrm{PI}(4,5) \mathrm{P} 2$ and $\mathrm{PI}(3,4,5) \mathrm{P} 3$ depleted relative to other areas of the plasma membrane in both cilia and the synapse. Primary cilia are specialized sensory organelles that extend from the plasma membrane into the extracellular space that are important for hedgehog and platelet derived growth factor signaling in cells. Primary cilia accumulate receptors in to a specialized region of the membrane concentrating many signaling molecules important for development (77-80). While cells readily produce primary cilia in response to stress or starvation, cells of the haemopoietic lineage do not. This is somewhat surprising as studies in immortalized B and T-cells have demonstrated that these hematopoietic cells do contain the machinery required to form cilia (81).

Cilia formation is dependent on the activities of Inpp5e and Inositol polyphosphate 5-phosphatase/OCRL1/Inpp5f (5' lipid phosphatases), which convert $\mathrm{PI}(4,5) \mathrm{P} 2$ and $\mathrm{PI}(3,4,5) \mathrm{P} 3$ into $\mathrm{PI}(4) \mathrm{P}$ and $\mathrm{PI}(3,4) \mathrm{P} 2$, respectively $(82-86)$. This acts to exclude concentrations of $\mathrm{PI}(4,5) \mathrm{P} 2$ and $\mathrm{PI}(3,4,5) \mathrm{P} 3$ to the transition zone at the basal body, in favor of $\mathrm{PI}(4) \mathrm{P}$ and possibly $\mathrm{PI}(3,4) \mathrm{P} 2$. The localization of $\mathrm{PI}(3,4) \mathrm{P} 2$ in the cilium is yet to be shown, but must be present if $\mathrm{PI}(3,4,5) \mathrm{P} 3$ is also converted (Figure 3). Furthermore, Bardet-Biedl Syndrome protein 5, part of a complex thought to transition G-protein coupled receptors into the cilium across the transition zone $(87)$, have PI(3,4)P2 binding $\mathrm{PH}$ domains implicating the presence of $\mathrm{PI}(3,4) \mathrm{P} 2$ in the cilium or as a regulator of protein transport to the cilium (88). Initiation of ciliary signaling and dissolution of cilia results in a shutdown of the lipid phosphatase pathway and production or 


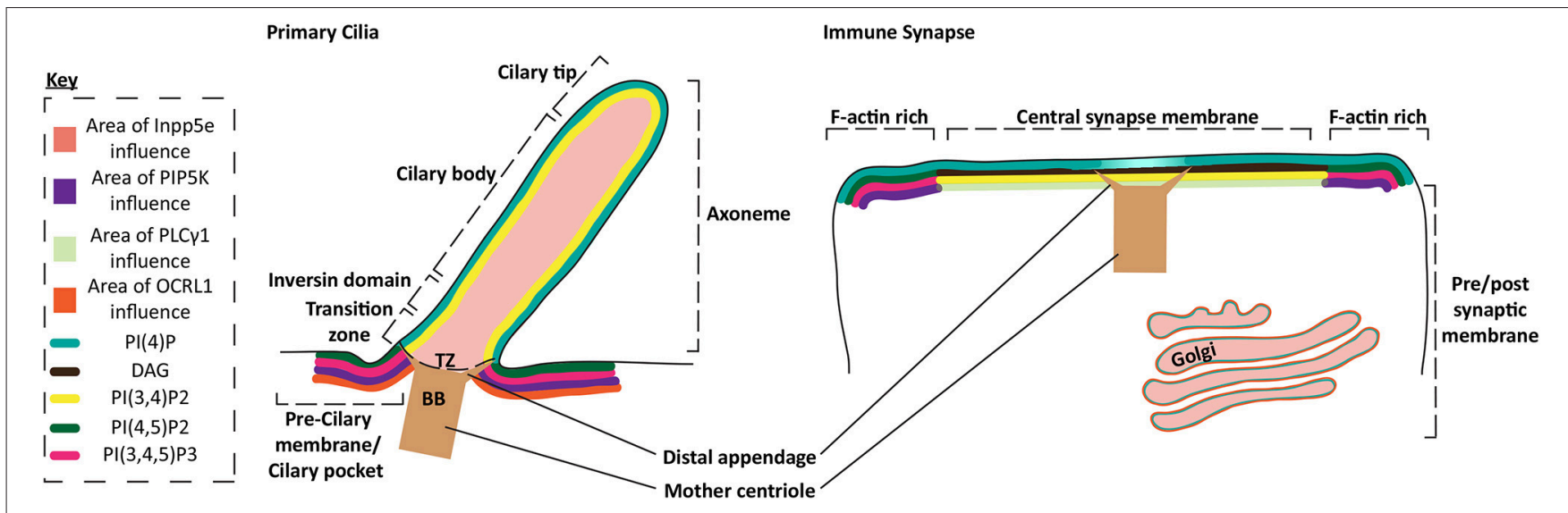

FIGURE 3 | Protein and phospholipid content of primary cilia and the immune synapse. Schematic of the membrane phospholipid content in the primary cilium and the immune synapse. Phospholipid enriched regions of the membrane are represented by the key, while protein areas of influence are also highlighted by colored membranes or regions. Specific membrane regions or ciliary domains are defined through bracketing. PI(3,4)P2 localization in the cilium is inferred from the description of $\mathrm{PI}(3,4,5) \mathrm{P} 3$ localization and the proposed activity of the Inpp5e in the cilium which converts $\mathrm{PI}(3,4,5) \mathrm{P} 3$ into $\mathrm{PI}(3,4) \mathrm{P} 2$, although this could diffuse away or be converted into other metabolites.

entry of $\mathrm{PI}(4,5) \mathrm{P} 2$ into the ciliary membrane. Actin is recruited to cilia after PI(4,5)P2 accumulation $(89,90)$. After lytic granule delivery, actin is also recovered over the synaptic membrane of CTLs. This suggests that actin is an effective barrier to signaling at the cilia and synapse (7). Interestingly the centrosome uses the interplay between PIP5K and Inpp5e to control the balance of PI(4)P and PI(4,5)P2 in either Golgi associated vesicles or at the plasma membrane. These lipids differentially regulate the recruitment of the distal appendage protein Cep164 or Tau tubulin kinase 2 to mediate ciliation after appropriate signaling occurs (91). In T cells PIP5K and levels of PI(4,5)P2 play a similar role in synapse formation (10). These findings highlight the similarities in membrane specialization in the immune synapse and cilia, supporting the idea that there may be a functional link between the structures.

After granule delivery to the CTL membrane both PI $(4,5) \mathrm{P} 2$ and actin are restored across the synapse. Likewise, it appears that actin is only present before formation or after dissolution of cilia $(90,92,93)$. This suggests actin may also act as a significant barrier in cilia, also regulated by changes in $\mathrm{PI}(4,5) \mathrm{P} 2$ and $\mathrm{PI}(3,4,5) \mathrm{P} 3$ (94) (Figure 3). Interestingly, actin dynamics slowed the flow of receptors transitioning between the cilium membrane and the plasma membrane peripheral to the cilia (93), while actin flow is also thought to play an important role in the coalescence of TCR clusters in T cells $(95,96)$.

\section{THE FUTURE OF LIPIDS AT THE SYNAPSE}

Phospholipids and their associated signaling molecules transmit information and support the accumulation of protein signaling

\section{REFERENCES}

1. La Gruta NL, Gras S, Daley SR, Thomas PG, Rossjohn J. Understanding the drivers of MHC restriction of $\mathrm{T}$ cell receptors. Nat Rev Immunol. (2018) 18:467-78. doi: 10.1038/s41577-0180007-5 platforms. They also shape the actin cytoskeleton and thereby sculpt higher order structures in cells. The lipases, kinases, and phosphatases involved in phospholipid metabolism shape the inner leaflet of the membrane without the need for structural proteins that mediate diffusion barriers. Many questions remain, and there are gaps in our knowledge that are not understood from the current literature, or via the use of exogenously expressed, available bio-probes. For example how do TCR complexes that depend on PI(4,5)P2 transition from the periphery, into the cSMAC, where $\mathrm{PI}(4,5) \mathrm{P} 2$ is depleted? Does depletion of phospholipid head groups result in significant biophysical changes in the membrane? Understanding these mechanisms will provide unique insights as to how regulators of granule delivery could be targeted, perhaps even therapeutically, and may also hold information that transfers to a diverse portfolio of cellular organelles in a diverse range of cells.

\section{AUTHOR CONTRIBUTIONS}

All authors listed have made a substantial, direct and intellectual contribution to the work, and approved it for publication.

\section{FUNDING}

Research was funded by Wellcome Trust grants [103930] and [100140], to GG. We would like to thank Katharina Strege, Phillipa Barton, Jane Stinchcombe, and Lyra Randzavola for critical reading of the manuscript.

2. Dieckmann NM, Frazer GL, Asano Y, Stinchcombe JC, Griffiths GM. The cytotoxic T lymphocyte immune synapse at a glance. J Cell Sci. (2016) 129:2881-6. doi: $10.1242 /$ jcs. 186205

3. Stinchcombe JC, Bossi G, Booth S, Griffiths GM. The immunological synapse of CTL contains a secretory domain and membrane bridges. Immunity. (2001) 15:751-61. doi: 10.1016/S1074-7613(01)00234-5 
4. Ritter AT, Angus KL, Griffiths GM. The role of the cytoskeleton at the immunological synapse. Immunol Rev. (2013) 256:107-17. doi: $10.1111 / \mathrm{imr} .12117$

5. Brown AC, Oddos S, Dobbie IM, Alakoskela JM, Parton RM, Eissmann P, et al. Remodelling of cortical actin where lytic granules dock at natural killer cell immune synapses revealed by super-resolution microscopy. PLoS Biol. (2011) 9:e1001152. doi: 10.1371/journal.pbio.1001152

6. Rak GD, Mace EM, Banerjee PP, Svitkina T, Orange JS. Natural killer cell lytic granule secretion occurs through a pervasive actin network at the immune synapse. PLoS Biol. (2011) 9:e1001151. doi: 10.1371/journal.pbio.1001151

7. Ritter AT, Asano Y, Stinchcombe JC, Dieckmann NM, Chen BC, GawdenBone $\mathrm{C}$, et al. Actin depletion initiates events leading to granule secretion at the immunological synapse. Immunity. (2015) 42:864-76. doi: 10.1016/j.immuni.2015.04.013

8. Ritter AT, Kapnick SM, Murugesan S, Schwartzberg PL, Griffiths GM, Lippincott-Schwartz J. Cortical actin recovery at the immunological synapse leads to termination of lytic granule secretion in cytotoxic T lymphocytes. Proc Natl Acad Sci USA. (2017) 114:E6585-94. doi: 10.1073/pnas.1710751114

9. Levin R, Grinstein S, Schlam D. Phosphoinositides in phagocytosis and macropinocytosis. Biochim Biophys Acta. (2015) 1851:805-23. doi: 10.1016/j.bbalip.2014.09.005

10. Gawden-Bone CM, Frazer GL, Richard AC, Ma CY, Strege K, Griffiths GM. PIP5 kinases regulate membrane phosphoinositide and actin composition for targeted granule secretion by cytotoxic lymphocytes. Immunity. (2018) 49:427-37.e4. doi: 10.1016/j.immuni.2018.08.017

11. Jenkins MR, Stinchcombe JC, Au-Yeung BB, Asano Y, Ritter AT, Weiss A, et al. Distinct structural and catalytic roles for Zap70 in formation of the immunological synapse in CTL. Elife. (2014) 3:e01310. doi: 10.7554/eLife.01310

12. Balagopalan L, Coussens NP, Sherman E, Samelson LE, Sommers CL. The LAT story: a tale of cooperativity, coordination, and choreography. Cold Spring Harb Perspect Biol. (2010) 2:a005512. doi: 10.1101/cshperspect.a005512

13. Balagopalan L, Kortum RL, Coussens NP, Barr VA, Samelson LE. The linker for activation of T cells (LAT) signaling hub: from signaling complexes to microclusters. J Biol Chem. (2015) 290:26422-9. doi: 10.1074/jbc.R115.665869

14. Kallikourdis M, Trovato AE, Roselli G, Muscolini M, Porciello N, Tuosto L, et al. Phosphatidylinositol 4-phosphate 5-kinase beta controls recruitment of lipid rafts into the immunological synapse. J Immunol. (2016) 196:1955-63. doi: 10.4049/jimmunol.1501788

15. Porciello N, Kunkl M, Viola A, Tuosto L. Phosphatidylinositol 4-phosphate 5-kinases in the regulation of T cell activation. Front Immunol. (2016) 7:186. doi: 10.3389/fimmu.2016.00186

16. Aikawa Y, Martin TF. ARF6 regulates a plasma membrane pool of phosphatidylinositol $(4,5)$ bisphosphate required for regulated exocytosis. $J$ Cell Biol. (2003) 162:647-59. doi: 10.1083/jcb.200212142

17. de Pereda JM, Wegener KL, Santelli E, Bate N, Ginsberg MH, Critchley DR, et al. Structural basis for phosphatidylinositol phosphate kinase type Igamma binding to talin at focal adhesions. J Biol Chem. (2005) 280:8381-6. doi: $10.1074 /$ jbc.M413180200

18. Halstead JR, Savaskan NE, van den Bout I, Van Horck F, Hajdo-Milasinovic A, Snell M, et al. Rac controls PIP5K localisation and PtdIns(4,5)P(2) synthesis, which modulates vinculin localisation and neurite dynamics. J Cell Sci. (2010) 123:3535-46. doi: 10.1242/jcs.062679

19. Nelson CD, Kovacs JJ, Nobles KN, Whalen EJ, Lefkowitz RJ. Beta-arrestin scaffolding of phosphatidylinositol 4-phosphate 5-kinase Ialpha promotes agonist-stimulated sequestration of the beta2-adrenergic receptor. J Biol Chem. (2008) 283:21093-101. doi: 10.1074/jbc.M800431200

20. van den Bout I, Divecha N. PIP5K-driven PtdIns(4,5)P2 synthesis: regulation and cellular functions. J Cell Sci. (2009) 122:3837-50. doi: 10.1242/jcs. 056127

21. Fairn GD, Ogata K, Botelho RJ, Stahl PD, Anderson RA, De Camilli P, et al. An electrostatic switch displaces phosphatidylinositol phosphate kinases from the membrane during phagocytosis. J Cell Biol. (2009) 187:701-14. doi: $10.1083 /$ jcb.200909025

22. Liu A, Sui D, Wu D, Hu J. The activation loop of PIP5K functions as a membrane sensor essential for lipid substrate processing. Sci Adv. (2016) 2:e1600925. doi: 10.1126/sciadv.1600925
23. Xu C, Xie H, Guo X, Gong H, Liu L, Qi H, et al. A PIP2-derived amplification loop fuels the sustained initiation of B cell activation. Sci Immunol. (2017) 2:eaan0787. doi: 10.1126/sciimmunol.aan0787

24. Chauveau A, Le Floc'h A, Bantilan NS, Koretzky GA, Huse M. Diacylglycerol kinase alpha establishes $\mathrm{T}$ cell polarity by shaping diacylglycerol accumulation at the immunological synapse. Sci Signal. (2014) 7:ra82. doi: 10.1126/scisignal.2005287

25. Sanjuan MA, Jones DR, Izquierdo M, Merida I. Role of diacylglycerol kinase alpha in the attenuation of receptor signaling. J Cell Biol. (2001) 153:207-20. doi: $10.1083 /$ jcb.153.1.207

26. Sanjuan MA, Pradet-Balade B, Jones DR, Martinez AC, Stone JC, GarciaSanz JA, et al. T cell activation in vivo targets diacylglycerol kinase alpha to the membrane: a novel mechanism for Ras attenuation. J Immunol. (2003) 170:2877-83. doi: 10.4049/jimmunol.170.6.2877

27. Merida I, Andrada E, Gharbi SI, Avila-Flores A. Redundant and specialized roles for diacylglycerol kinases alpha and zeta in the control of $\mathrm{T}$ cell functions. Sci Signal. (2015) 8:re6. doi: 10.1126/scisignal.aaa0974

28. Corbalan-Garcia S, Gomez-Fernandez JC. Protein kinase C regulatory domains: the art of decoding many different signals in membranes. Biochim Biophys Acta. (2006) 1761:633-54. doi: 10.1016/j.bbalip.2006.04.015

29. Corbalan-Garcia S, Gomez-Fernandez JC. Signaling through C2 domains: more than one lipid target. Biochim Biophys Acta. (2014) 1838:1536-47. doi: 10.1016/j.bbamem.2014.01.008

30. El Amri M, Fitzgerald U, Schlosser G. MARCKS and MARCKS-like proteins in development and regeneration. J Biomed Sci. (2018) 25:43. doi: 10.1186/s12929-018-0445-1

31. Lemmon MA. Membrane recognition by phospholipid-binding domains. Nat Rev Mol Cell Biol. (2008) 9:99-111. doi: 10.1038/nrm2328

32. Yeung T, Gilbert GE, Shi J, Silvius J, Kapus A, Grinstein S. Membrane phosphatidylserine regulates surface charge and protein localization. Science. (2008) 319:210-3. doi: 10.1126/science.1152066

33. Ma Y, Yamamoto Y, Nicovich PR, Goyette J, Rossy J, Gooding JJ, et al. A FRET sensor enables quantitative measurements of membrane charges in live cells. Nat Biotechnol. (2017) 35:363-70. doi: 10.1038/nbt.3828

34. Roy MO, Leventis R, Silvius JR. Mutational and biochemical analysis of plasma membrane targeting mediated by the farnesylated, polybasic carboxy terminus of K-ras4B. Biochemistry. (2000) 39:8298-307. doi: 10.1021/bi000512q

35. Basu R, Huse M. Mechanical communication at the immunological synapse. Trends Cell Biol. (2017) 27:241-54. doi: 10.1016/j.tcb.2016.10.005

36. Kumari S, Depoil D, Martinelli R, Judokusumo E, Carmona G, Gertler $\mathrm{FB}$, et al. Actin foci facilitate activation of the phospholipase Cgamma in primary T lymphocytes via the WASP pathway. Elife. (2015) 4. doi: 10.7554/eLife.04953

37. Janmey PA, Bucki R, Radhakrishnan R. Regulation of actin assembly by $\mathrm{PI}(4,5) \mathrm{P} 2$ and other inositol phospholipids: an update on possible mechanisms. Biochem Biophys Res Commun. (2018) 506:307-14. doi: 10.1016/j.bbrc.2018.07.155

38. Faure S, Salazar-Fontana LI, Semichon M, Tybulewicz VL, Bismuth G, Trautmann A, et al. ERM proteins regulate cytoskeleton relaxation promoting T cell-APC conjugation. Nat Immunol. (2004) 5:272-9. doi: 10.1038/ni1039

39. Hao JJ, Liu Y, Kruhlak M, Debell KE, Rellahan BL, Shaw S. Phospholipase C-mediated hydrolysis of PIP2 releases ERM proteins from lymphocyte membrane. J Cell Biol. (2009) 184:451-62. doi: 10.1083/jcb.200807047

40. Sun Y, Dandekar RD, Mao YS, Yin HL, Wulfing C. Phosphatidylinositol $(4,5)$ bisphosphate controls $\mathrm{T}$ cell activation by regulating $\mathrm{T}$ cell rigidity and organization. PLoS ONE. (2011) 6:e27227. doi: 10.1371/journal.pone.0027227

41. Shaffer MH, Dupree RS, Zhu P, Saotome I, Schmidt RF, McClatchey AI, et al. Ezrin and moesin function together to promote $\mathrm{T}$ cell activation. J Immunol. (2009) 182:1021-32. doi: 10.4049/jimmunol.182.2.1021

42. Le Floc'h A, Tanaka Y, Bantilan NS, Voisinne G, Altan-Bonnet G, Fukui Y, et al. Annular PIP3 accumulation controls actin architecture and modulates cytotoxicity at the immunological synapse. J Exp Med. (2013) 210:2721-37. doi: 10.1084/jem.20131324

43. Basu R, Whitlock BM, Husson J, Le Floc'h A, Jin W, Oyler-Yaniv A, et al. Cytotoxic T cells use mechanical force to potentiate target cell killing. Cell. (2016) 165:100-10. doi: 10.1016/j.cell.2016.01.021 
44. Moretti FA, Moser M, Lyck R, Abadier M, Ruppert R, Engelhardt B, et al. Kindlin-3 regulates integrin activation and adhesion reinforcement of effector T cells. Proc Natl Acad Sci USA. (2013) 110:17005-10. doi: 10.1073/pnas.1316032110

45. Ni T, Kalli AC, Naughton FB, Yates LA, Naneh O, Kozorog M, et al. Structure and lipid-binding properties of the kindlin-3 pleckstrin homology domain. Biochem J. (2017) 474:539-56. doi: 10.1042/BCJ20160791

46. Fagerholm SC, Lek HS, Morrison VL. Kindlin-3 in the immune system. Am J Clin Exp Immunol. (2014) 3:37-42.

47. Moretti FA, Klapproth S, Ruppert R, Margraf A, Weber J, Pick R, et al. Differential requirement of kindlin-3 for $\mathrm{T}$ cell progenitor homing to the non-vascularized and vascularized thymus. Elife. (2018) 7:e35816. doi: 10.7554/eLife.35816

48. Morrison VL, MacPherson M, Savinko T, Lek HS, Prescott A, Fagerholm SC. The beta2 integrin-kindlin-3 interaction is essential for T-cell homing but dispensable for T-cell activation in vivo. Blood. (2013) 122:1428-36. doi: 10.1182/blood-2013-02-484998

49. Jankowska KI, Williamson EK, Roy NH, Blumenthal D, Chandra V, Baumgart $\mathrm{T}$, et al. Integrins modulate $\mathrm{T}$ cell receptor signaling by constraining actin flow at the immunological synapse. Front Immunol. (2018) 9:25. doi: 10.3389/fimmu.2018.00025

50. Comrie WA, Babich A, Burkhardt JK. F-actin flow drives affinity maturation and spatial organization of LFA-1 at the immunological synapse. J Cell Biol. (2015) 208:475-91. doi: 10.1083/jcb.201406121

51. Comrie WA, Li S, Boyle S, Burkhardt JK. The dendritic cell cytoskeleton promotes $\mathrm{T}$ cell adhesion and activation by constraining ICAM-1 mobility. J Cell Biol. (2015) 208:457-73. doi: 10.1083/jcb.201406120

52. Yu CH, Wu HJ, Kaizuka Y, Vale RD, Groves JT. Altered actin centripetal retrograde flow in physically restricted immunological synapses. PLoS ONE. (2010) 5:e11878. doi: 10.1371/journal.pone.0011878

53. Santos LC, Blair DA, Kumari S, Cammer M, Iskratsch T, Herbin $\mathrm{O}$, et al. Actin polymerization-dependent activation of Cas- $\mathrm{L}$ promotes immunological synapse stability. Immunol Cell Biol. (2016) 94:981-93. doi: $10.1038 /$ icb.2016.61

54. Bachmann MF, McKall-Faienza K, Schmits R, Bouchard D, Beach J, Speiser DE, et al. Distinct roles for LFA-1 and CD28 during activation of naive T cells: adhesion versus costimulation. Immunity. (1997) 7:549-57. doi: 10.1016/S1074-7613(00)80376-3

55. Roy NH, Burkhardt JK. Embracing the enemy: cell-to-cell force transmission enhances cytotoxicity. Dev Cell. (2016) 36:592-4. doi: 10.1016/j.devcel.2016.03.007

56. Liu X, Kapoor TM, Chen JK, Huse M. Diacylglycerol promotes centrosome polarization in $\mathrm{T}$ cells via reciprocal localization of dynein and myosin II. Proc Natl Acad Sci USA. (2013) 110:11976-81. doi: 10.1073/pnas. 1306180110

57. Quann EJ, Liu X, Altan-Bonnet G, Huse M. A cascade of protein kinase C isozymes promotes cytoskeletal polarization in T cells. Nat Immunol. (2011) 12:647-54. doi: $10.1038 /$ ni.2033

58. Quann EJ, Merino E, Furuta T, Huse M. Localized diacylglycerol drives the polarization of the microtubule-organizing center in T cells. Nat Immunol. (2009) 10:627-35. doi: 10.1038/ni.1734

59. Joseph N, Reicher B, Barda-Saad M. The calcium feedback loop and $\mathrm{T}$ cell activation: how cytoskeleton networks control intracellular calcium flux. Biochim Biophys Acta. (2014) 1838:557-68. doi: 10.1016/j.bbamem.2013.07.009

60. Alwarawrah M, Dai J, Huang J. Modification of lipid bilayer structure by diacylglycerol: a comparative study of diacylglycerol and cholesterol. J Chem Theory Comput. (2012) 8:749-58. doi: 10.1021/ ct200790q

61. Ebinu JO, Stang SL, Teixeira C, Bottorff DA, Hooton J, Blumberg PM, et al. RasGRP links T-cell receptor signaling to Ras. Blood. (2000) 95:3199-203.

62. Spitaler M, Emslie E, Wood CD, Cantrell D. Diacylglycerol and protein kinase D localization during T lymphocyte activation. Immunity. (2006) 24:535-46. doi: 10.1016/j.immuni.2006.02.013

63. Navarro MN, Goebel J, Hukelmann JL, Cantrell DA. Quantitative phosphoproteomics of cytotoxic $\mathrm{T}$ cells to reveal protein kinase d 2 regulated networks. Mol Cell Proteomics. (2014) 13:3544-57. doi: $10.1074 /$ mcp.M113.037242
64. Huang YH, Grasis JA, Miller AT, Xu R, Soonthornvacharin S, Andreotti AH, et al. Positive regulation of Itk PH domain function by soluble IP4. Science. (2007) 316:886-9. doi: 10.1126/science.1138684

65. Kapnick SM, Stinchcombe JC, Griffiths GM, Schwartzberg PL. Inducible $\mathrm{T}$ cell kinase regulates the acquisition of cytolytic capacity and degranulation in CD8(+) CTLs. J Immunol. (2017) 198:2699-711. doi: 10.4049/jimmunol.1601202

66. Mukherjee S, Rigaud S, Seok SC, Fu G, Prochenka A, Dworkin M, et al. In silico modeling of Itk activation kinetics in thymocytes suggests competing positive and negative IP4 mediated feedbacks increase robustness. PLoS ONE. (2013) 8:e73937. doi: 10.1371/journal.pone. 0073937

67. Bach TL, Kerr WT, Wang Y, Bauman EM, Kine P, Whiteman EL, et al. PI3K regulates pleckstrin-2 in T-cell cytoskeletal reorganization. Blood. (2007) 109:1147-55. doi: 10.1182/blood-2006-02-001339

68. Ma Y, Poole K, Goyette J, Gaus K. Introducing membrane charge and membrane potential to $\mathrm{T}$ cell signaling. Front Immunol. (2017) 8:1513. doi: 10.3389/fimmu.2017.01513

69. Kay JG, Koivusalo M, Ma X, Wohland T, Grinstein S. Phosphatidylserine dynamics in cellular membranes. Mol Biol Cell. (2012) 23:2198-212. doi: 10.1091/mbc.e11-11-0936

70. Jenkins GH, Fisette PL, Anderson RA. Type I phosphatidylinositol 4phosphate 5-kinase isoforms are specifically stimulated by phosphatidic acid. J Biol Chem. (1994) 269:11547-54.

71. Varnai P, Gulyas G, Toth DJ, Sohn M, Sengupta N, Balla T. Quantifying lipid changes in various membrane compartments using lipid binding protein domains. Cell Calcium. (2017) 64:72-82. doi: 10.1016/j.ceca.2016. 12.008

72. Shim H, Wu C, Ramsamooj S, Bosch KN, Chen Z, Emerling BM, et al. Deletion of the gene Pip $4 \mathrm{k} 2 \mathrm{c}$, a novel phosphatidylinositol kinase, results in hyperactivation of the immune system. Proc Natl Acad Sci USA. (2016) 113:7596-601. doi: 10.1073/pnas. 1600934113

73. Tronchere H, Laporte J, Pendaries C, Chaussade C, Liaubet L, Pirola L, et al. Production of phosphatidylinositol 5-phosphate by the phosphoinositide 3phosphatase myotubularin in mammalian cells. J Biol Chem. (2004) 279:730412. doi: $10.1074 /$ jbc.M311071200

74. Ungewickell A, Hugge C, Kisseleva M, Chang SC, Zou J, Feng Y, et al. The identification and characterization of two phosphatidylinositol-4,5bisphosphate 4-phosphatases. Proc Natl Acad Sci USA. (2005) 102:18854-9. doi: 10.1073/pnas.0509740102

75. Guittard G, Mortier E, Tronchere H, Firaguay G, Gerard A, Zimmermann P, et al. Evidence for a positive role of PtdIns5P in T-cell signal transduction pathways. FEBS Lett. (2010) 584:2455-60. doi: 10.1016/j.febslet.2010. 04.051

76. Nunes JA, Guittard G. An emerging role for PI5P in T cell biology. Front Immunol. (2013) 4:80. doi: 10.3389/fimmu.2013.00080

77. Briscoe J, Therond PP. The mechanisms of Hedgehog signalling and its roles in development and disease. Nat Rev Mol Cell Biol. (2013) 14:416-29. doi: $10.1038 / \mathrm{nrm} 3598$

78. Christensen ST, Clement CA, Satir P, Pedersen LB. Primary cilia and coordination of receptor tyrosine kinase (RTK) signalling. J Pathol. (2012) 226:172-84. doi: 10.1002/path.3004

79. Satir P, Pedersen LB, Christensen ST. The primary cilium at a glance. J Cell Sci. (2010) 123:499-503. doi: $10.1242 /$ jcs.050377

80. Wang L, Dynlacht BD. The regulation of cilium assembly and disassembly in development and disease. Development. (2018) 145:dev151407. doi: 10.1242/dev.151407

81. Prosser SL, Morrison CG. Centrin2 regulates CP110 removal in primary cilium formation. J Cell Biol. (2015) 208:693-701. doi: 10.1083/jcb.201411070

82. Chavez M, Ena S, Van Sande J, de Kerchove d'Exaerde A, Schurmans S, Schiffmann S. N. Modulation of ciliary phosphoinositide content regulates trafficking and sonic hedgehog signaling output. Dev Cell. (2015) 34:338-50. doi: 10.1016/j.devcel.2015.06.016

83. Dyson JM, Conduit SE, Feeney SJ, Hakim S, DiTommaso T, Fulcher $\mathrm{AJ}$, et al. INPP5E regulates phosphoinositide-dependent cilia transition zone function. J Cell Biol. (2017) 216:247-63. doi: 10.1083/jcb.2015 11055 
84. Garcia-Gonzalo FR, Phua SC, Roberson EC, Garcia G III, Abedin M, Schurmans $\mathrm{S}$, Inoue $\mathrm{T}$, et al. Phosphoinositides regulate ciliary protein trafficking to modulate hedgehog signaling. Dev Cell. (2015) 34:400-9. doi: 10.1016/j.devcel.2015.08.001

85. Hakim S, Dyson JM, Feeney SJ, Davies EM, Sriratana A, Koenig MN, et al. Inpp5e suppresses polycystic kidney disease via inhibition of PI3K/Aktdependent mTORC1 signaling. Hum Mol Genet. (2016) 25:2295-313. doi: 10.1093/hmg/ddw097

86. Jensen VL, Li C, Bowie RV, Clarke L, Mohan S, Blacque OE, et al. Formation of the transition zone by Mks5/Rpgrip1L establishes a ciliary zone of exclusion (CIZE) that compartmentalises ciliary signalling proteins and controls PIP2 ciliary abundance. EMBO J. (2015) 34:2537-56. doi: 10.15252/embj.201488044

87. Klink BU, Zent E, Juneja P, Kuhlee A, Raunser S, Wittinghofer A. A recombinant BBSome core complex and how it interacts with ciliary cargo. Elife. (2017) 6:e27434. doi: 10.7554/eLife.27434

88. Jin H, White SR, Shida T, Schulz S, Aguiar M, Gygi SP, et al. The conserved Bardet-Biedl syndrome proteins assemble a coat that traffics membrane proteins to cilia. Cell. (2010) 141:1208-19. doi: 10.1016/j.cell.2010. 05.015

89. Nager AR, Goldstein JS, Herranz-Perez V, Portran D, Ye F, GarciaVerdugo JM, et al. An actin network dispatches ciliary GPCRs into extracellular vesicles to modulate signaling. Cell. (2017) 168:252-63 e214. doi: 10.1016/j.cell.2016.11.036

90. Phua SC, Chiba S, Suzuki M, Su E, Roberson EC, Pusapati GV, et al. Dynamic remodeling of membrane composition drives cell cycle through primary cilia excision. Cell. (2017) 168:264-79 e215. doi: 10.1016/j.cell.2016.12.032

91. Xu Q, Zhang Y, Wei Q, Huang Y, Hu J, Ling K. Phosphatidylinositol phosphate kinase PIPKIgamma and phosphatase INPP5E coordinate initiation of ciliogenesis. Nat Commun. (2016) 7:10777. doi: 10.1038/ ncomms 10777

92. Avasthi P, Marshall WF. Stages of ciliogenesis and regulation of ciliary length. Differentiation. (2012) 83:S30-42. doi: 10.1016/j.diff.2011.11.015

93. Lee S, Tan HY, Geneva II, Kruglov A, Calvert PD. Actin filaments partition primary cilia membranes into distinct fluid corrals. J Cell Biol. (2018) 217:2831-49. doi: 10.1083/jcb.201711104

94. Phua SC, Nihongaki Y, Inoue T. Autonomy declared by primary cilia through compartmentalization of membrane phosphoinositides. Curr Opin Cell Biol. (2018) 50:72-8. doi: 10.1016/j.ceb.2018.01.008

95. Hashimoto-Tane A, Saito T. Dynamic regulation of TCR-microclusters and the microsynapse for T cell activation. Front Immunol. (2016) 7:255. doi: 10.3389/fimmu.2016.00255

96. Kaizuka Y, Douglass AD, Varma R, Dustin ML, Vale RD. Mechanisms for segregating $\mathrm{T}$ cell receptor and adhesion molecules during immunological synapse formation in Jurkat T cells. Proc Natl Acad Sci USA. (2007) 104:20296-301. doi: 10.1073/pnas.0710258105

Conflict of Interest Statement: The authors declare that the research was conducted in the absence of any commercial or financial relationships that could be construed as a potential conflict of interest.

Copyright (c) 2019 Gawden-Bone and Griffiths. This is an open-access article distributed under the terms of the Creative Commons Attribution License (CC BY). The use, distribution or reproduction in other forums is permitted, provided the original author(s) and the copyright owner(s) are credited and that the original publication in this journal is cited, in accordance with accepted academic practice. No use, distribution or reproduction is permitted which does not comply with these terms. 